7?

columns after commencing lithium. The symptoms disappeared after lithium treatment was terminated, despite the continuation of high, but reducing, doses of paroxetine. Muly et al (1993) describe a similar case in which lithium was used in addition to fluoxetine. Similar to the case described here, the symptoms resolved by withdrawal of lithium, despite continuation of antidepressant treatment. This can be explained by the hypothesis that lithium acts to enhance serotoninergic function as described expansively by Price et al (1990) in their review article of a large body of clinical evidence. In conclusion, it is important to remember that, while lithium is generally a well tolerated drug, there have been increasing reports demonstrating that on addition to a stable SSRI regime, mindfulness of the possibility of serotonin syndrome is essential.

MULY, C. E., MCDONALD, W., STEFFENS, D., et al (1993) Serotonin syndrome produced by a combination of fluoxetine and lithium. American Journal of Psychiatry, 150, 1565

PRICE, L. H., CHARNEY, D. S., DELGADO, P., et al (1990) Lithium and serotonin function: implications for the serotonin hypothesis of depression. Psychopharmacology, 100, 2-12.

Emma J. Watts Senior House Officer , Farida Yousaf Consultant Psychiatrist, Department of Psychiatry, Langley Wing, Epsom General Hospital, Dorking Road, Epsom, Surrey KT18 7EG

\section{Monitoring of seizures during electroconvulsive therapy by the 'cuff' method is still relevant today}

Sir: Jan Wise et al (Psychiatric Bulletin, August 2000, 24, 301) suggest that the use of the cuff method to 'observe' absent seizures during electroconvulsive therapy (ECT) should cease. They based their findings on the fact that there were no differences in the duration of seizures in the cuffed arm and the uncuffed arm. One fails to understand how this would happen if they were using an adequate dose of muscle relaxants. The methodology does not describe the nature or dose of neuromuscular blocking agent used. The authors also need to look at the possibility of a type-II error in view of the small number of ECT episodes included in the study.

It is worthwhile pointing out that the cuff method is not used to merely 'observe' absent seizures, but to monitor inadequate seizures as well as to detect status epilepticus, which can prove fatal if undetected. It is true that electroencephalogram (EEG) monitoring remains the standard, but resource implications mean that most centres in this country will have to manage with the cuff method. I was involved in a study where we found a strong correlation between duration of seizures as measured by the cuff method and by EEG monitoring. Several authors have replicated this finding.

The monitoring of seizures by the cuff method cannot be entirely dismissed and remains relevant to psychiatric practice today because of its cost-effectiveness.

AN WISE, M. E., MACKIE, F., ZAMAR, A. C., et a (2000) Investigation of the 'cuff' method for assessing seizure duration in electroconvulsive therapy. Psychiatric Bulletin, 24, 301.

Prabhat Mahapatra Specialist Registrar in Psychiatry, Bristol Central Community Learning DifficultiesTeam, New Friends Hall, Heath House Lane, Stapleton, Bristol BS161EQ

Sir: I read with interest the article by Jan Wise et al (Psychiatric Bulletin, August 2000, 24, 301). The authors cast doubts about using the Hamilton cuff method for assessing seizure duration and recommended EEG monitoring as a standard procedure need of ECT. EEG seizure monitoring indeed helps to prevent unwarranted restimulation as well as detecting prolonged seizures (Mayur et al, 1999), however the use of the cuff technique needs to be viewed in terms of its benefit and risk, especially in places where EEG monitoring is not available. Jan Wise et al have not reported the dosage of the muscle relaxants used. For patients who require high dose of succinylcholine, $>1.0 \mathrm{mg} / \mathrm{kg}$, (eg. patients with bone and joint problems who require complete muscle paralysis, or patients who need longer ECT session for stimulus dose titration), seizure could be masked. In addition, the finding that there was no significant difference in seizure duration between cuffed and uncuffed limbs could be limited by a lack of blindness between three observers. All raters were using a similar approach to note the seizure duration at the same time and place.

I have reservation in disregarding the cuff technique and would rather support the College recommendation (Royal College of Psychiatrists, 1995) that cuff duration should be kept to a minimum and the cuff inflation should be released as soon as adequate seizure duration has occurred. Care also needs to be taken for patients with severe osteoporosis, other major orthopaedic problems and sickle cell disease (Weiner et al, 1991)

MAYUR, P. M., GANGADHAR, B. N., IANAKIRAMAIAH, N., et al (1999) Motor seizure monitoring during electroconvulsive therapy. British Journal of Psychiatry, 174, 270-272.

ROYAL COLLEGE OF PSYCHIATRISTS (1995) The ECT Handbook. Second Report of the Royal College of Psychiatrists' Special Committee on ECT. London: Royal College of Psychiatrists.
WEINER, R. D. COFFEY, C. E. \& KRYSTAL, A. D. (1991) The monitoring and management of electrically induced seizures. Psychiatric Clinics of North America, $14,845-869$

K. F. Chung Assistant Professor, Department of Psychiatry, The University of Hong Kong, Pokfulam Road, Hong Kong SAR, China (Tel.: +86 852 28554487; Fax: +86 852 28551345; e-mail:kfchung@kucc.hku.hk)

\section{Suicide and the internet}

Sir: In his paper on the potential influence of the internet on suicide, Thompson (1999) considered the availability of dangerous information and the existence of certain sites advocating suicide. Several cases of completed suicide, using methods described on the internet, have been reported since the first such UK report on the subject in 1998 (Haut). We wish to report a case in which the internet's rapidly developing market-place provided the drug employed in a successful suicide.

The patient, a thirty-four year old male, was admitted after an overdose of clomipramine. This had been obtained from an overseas pharmacy, which sold prescription-only drugs on the internet without the need for a prescription. After discharge, the man took a second and fata overdose of clomipramine that had been obtained, against our advice, from the same source. We were surprised at the ease with which it is possible to obtain a wide range of prescription-only drugs via the internet. One site, for example, offered a list of overseas pharmacies and included advice on how to avoid legal difficulties in obtaining drugs from them

The sale of prescription drugs in the UK is controlled by the Medicines Act, but the purchase of such drugs from overseas pharmacies seems to fall into a legal grey area. All that UK authorities can currently do is stop such medications at customs control. It has recently been reported in the press that the Medicines Control Agency and the National Criminal Intelligence Service are starting to work with other countries to develop international standards to control the sale of drugs on the internet.

The internet can provide both the information and the physical means enabling people to commit suicide. We are used to considering our clients' use of illegal substances or legally obtained prescription drugs, but increasingly we may need to be aware of their use of illegally obtained prescription drugs.

HAUT, F. (1998) The Internet and the future of psychiatry (letter). Psychiatric Bulletin, 22, 641-642.

THOMPSON, S. (1999) The Internet and its potential influence on suicide. Psychiatric Bulletin, 23, 449-351.

*S Beatson Senior House Officer in Psychiatry, G S Hosty and S Smith Consultant Psychiatrists, Shelton Hospital, Bicton Heath, Shrewsbury SY3 8DN 